\title{
Interaction Between Semantic and Orthographic Factors in Conceptually Driven Naming: Comment on Starreveld and La Heij (1995)
}

\author{
Ardi Roelofs, Antje S. Meyer, and Willem J. M. Levelt \\ Max Planck Institute for Psycholinguistics
}

\begin{abstract}
P. A. Starreveld and W. La Heij (1995) tested the seriality view of lexical access in speech production, according to which lexical selection and the encoding of a word's form proceed in serial order without feedback. In 2 experiments, they looked at the combined effect of semantic and orthographic relatedness of written distractor words in tasks that required conceptually driven naming. They found an interaction between semantic relatedness and orthographic relatedness and argued that the observed interaction refutes the seriality view of lexical access. In this comment, the authors argue that Starreveld and La Heij's rejection of serial access was based on an oversimplified conception of the seriality view and that interaction, rather than additivity, is predicted by existing conceptions of serial access.
\end{abstract}

In two experiments, a picture naming and a definition naming experiment, Starreveld and La Heij (1995) observed an interaction between semantic and orthographic relatedness of written distractor words. They concluded that these findings refute a model of lexical access in speech production in which lexical selection (hereafter referred to as lemma retrieval) and word-form encoding (hereafter referred to as phonological encoding) occur in serial order without feedback (e.g., Levelt et al., 1991a, 1991b; Schriefers, Meyer, \& Levelt, 1990). According to Starreveld and La Heij, the seriality view "predicts additive effects of semantic similarity and orthographic similarity. The present study showed this prediction to be incorrect" (Starreveld \& La Heij, 1995, p. 694). In this comment, we argue that their rejection was based on a wrong conception of the seriality view, and that the observed interaction can readily be obtained within a serial model of lexical access.

\section{Starreveld and La Heij's (1995) Argument}

In two experiments, Starreveld and La Heij (1995) examined the joint effect of semantic and orthographic relatedness of visual distractor words in tasks that required conceptually driven naming. Thereby, they followed up a seminal study by Rayner and Springer (1986). Starreveld and La Heij argued that examining the combined effect of semantic and orthographic relatedness is of theoretical importance in light of the recent debate concerning the issue of seriality in lexical access in speech production (e.g., Dell \& O'Seaghdha, 1991; Levelt et al., 1991a, 1991b). In one experiment, Starreveld and La Heij asked participants to produce words when given definitions of their meanings. In another experiment, participants had to

Ardi Roelofs, Antje S. Meyer, and Willem J. M. Levelt, Max Planck Institute for Psycholinguistics, Nijmegen, The Netherlands.

Correspondence concerning this article should be addressed to Ardi Roelofs, Max Planck Institute for Psycholinguistics, Wundtlaan 1, 6525 XD, Nijmegen, The Netherlands. Electronic mail may be sent via Internet to ardi@mpi.nl. name pictured objects; for example, they had to name a pictured cat while trying to ignore a written word superimposed on the picture. Starreveld and $\mathrm{La} \mathrm{Heij} \mathrm{observed} \mathrm{an}$ inhibitory effect from semantically related distractor words (e.g., horse) compared with semantically unrelated distractor words (e.g., house) and a facilitatory effect from orthographically related distractors (e.g., cap) relative to orthographically unrelated ones (e.g., house). Thus, Starreveld and La Heij replicated two classical findings (e.g., Lupker, 1982; MacLeod, 1991). Most important, semantic and orthographic relatedness interacted with each other: The semantic inhibition effect was smaller when the target and distractor were orthographically related (target cat; distractor calf vs. cap) than when they were unrelated in form (target cat; distractor horse vs. house). A similar pattern of results has been obtained by Rayner and Springer (1986).

According to Starreveld and La Heij (1995) the interaction between semantic and orthographic relatedness refutes a view of lexical access according to which phonological encoding follows lemma retrieval in serial order without feedback. In particular, according to them, the interaction suggests that the process of lemma retrieval does not exist, or does not play a role in picture naming, or that, if it exists (which is the received view in psycholinguistics), lemma retrieval is influenced by feedback from phonological encoding. If one dispenses with lemma retrieval (i.e., if concepts are mapped directly onto phonological forms), both semantic and orthographic factors may affect phonological encoding (which would then coincide with lexical selection). Because these factors influence the same stage, an interaction may be expected. If a lemma level exists that is affected by semantic relatedness and by feedback from phonological encoding, and if orthographic relatedness affects the phonological level (the written words in Starreveld and La Heij's experiments were not only orthographically but also phonologically related), an interaction may be expected as well. However, whether an interaction will actually occur depends on the specific way the two factors combine, as Starreveld and $\mathrm{La} \mathrm{Heij} \mathrm{admitted.} \mathrm{The} \mathrm{prediction} \mathrm{of} \mathrm{an} \mathrm{interac-}$ 
tion is not a logical necessity on these accounts. In this respect, the additive factors logic used by Starreveld and La Heij is not a very strong one. According to Sternberg (1969), "by and large, factors that influence different stages will have additive effects on mean RT, whereas factors that influence stages in common will interact" (p. 282). The problem is, however, that "in situations where stages have some independent definition, it is perfectly conceivable that two factors might affect a single stage in an additive manner or that they might affect different stages and interact" (Pachella, 1974, p. 58). If semantic relatedness only affects the lemma level and orthographic relatedness only affects the phonological level, the effects of semantic and orthographic relatedness may (but need not) be additive. Again, the prediction of additivity is not a logical necessity, but depends on the specific assumptions entering a serial model.

\section{Why Serial Access Does Not Predict Additive Effects}

Starreveld and La Heij's (1995) argument against serial access looks rather straightforward. However, we believe that there is one major flaw in their line of reasoning: In existing serial models, orthographic relatedness does not affect the phonological level alone, but affects lemma retrieval as well. Because both semantic and orthographic factors affect lemma retrieval, their combined effects do not have to be additive.

We lay out our argument using the model of lexical access proposed by Roelofs $(1992,1993)$. This computational model was designed to account for semantic effects from written distractor words obtained in picture-word interference experiments. Figure 1 depicts the mental stages that are assumed to be engaged in picture-word interference (modeled after Figure 1 in Roelofs, 1992).

According to this model, the mental lexicon is a network of nodes and links that is accessed by spreading activation. Figure 2 depicts a small fragment of the lexical network. The network consists of three strata: a conceptual stratum with lexicalconcept nodes and links (e.g., CAT(X), HORSE(X)); a syntactic stratum with lemma nodes (e.g., cat); and word-form strata with orthographic nodes and links (e.g., c, a, t, cat) as well as phonological nodes and links (e.g., / kæt/,/k/, /æe/,/t/). The model distinguishes between input orthographic representations (involved in the input stage referred to as word-form perception in Figure 1) and output phonological representations (involved in the output stage referred to as phonological encoding). We return to this characteristic of the model below.

In the model, a written distractor word triggers both lemma retrieval (Route a in Figure 1) and phonological encoding (Route b in Figure 1). "A written word will activate both its lemma and its articulatory program" (Roelofs, 1992, p. 115; see also Figures 1, 2, and 3 of that article). Activation of lemmas by orthographic codes is at the heart of the model's account of semantic effects. If the distractor lemmas were not activated, target retrieval should not be more difficult after a semantically related than after an unrelated distractor.

Roelofs' $(1992,1993)$ model explains the semantic inhibition effects in picture-word interference experiments roughly as follows (for details, see the original articles). If horse is superimposed as a written distractor on a pictured cat, the

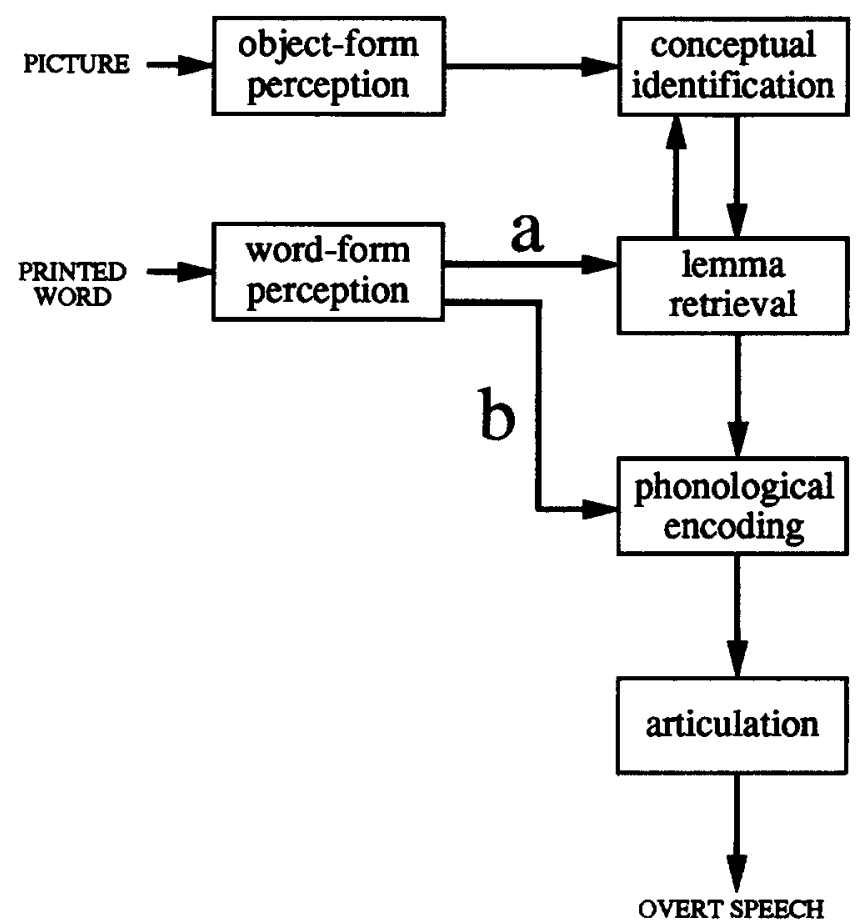

Figure 1. Stages of mental processing engaged in the picture-word interference paradigm (modeled after Roelofs, 1992). Boxes denote processing stages and arrows indicate the flow of information through the system.

activation from the picture and from the distractor word will converge in the network on the lemma node of the distractor word horse. This is because $\operatorname{CAT}(\mathrm{x})$ and $\operatorname{HORSE}(\mathrm{x})$ are connected at the conceptual stratum. A semantically related distractor activates the target, but this activation is smaller than the activation of the distractor lemma by the picture (as a result of network distances). If house is superimposed, there will be no convergence of activation, because HOUSE( $x)$ and CAT(X) are not connected at the conceptual stratum. As a result, the lemma of the distractor horse will be a stronger competitor to the target lemma cat than the lemma of the distractor house.

In the research on visual word recognition, the role of phonology is a hotly debated issue. Furthermore, there is much discussion about whether Route $b$ in Figure 1 is a single route (e.g., Seidenberg \& McClelland, 1989) or whether it comprises a lexically mediated mapping and a nonlexical mapping between print and speech (e.g., Coltheart, Curtis, Atkins, \& Haller, 1993). However, most "theories share the idea that processing occurs along both visual and phonological pathways in parallel and that each route determines meaning at least some of the time" (Jared \& Seidenberg, 1991, p. 358). In silent reading, phonological mediation can engage either input units (e.g., those units also involved in comprehending spoken words) or output units. (Of course, in reading aloud, phonological output representations are involved.) In a serial model of lexical access in speaking, there is no feedback from the phonological output level to the lemma level. Thus, in such a 


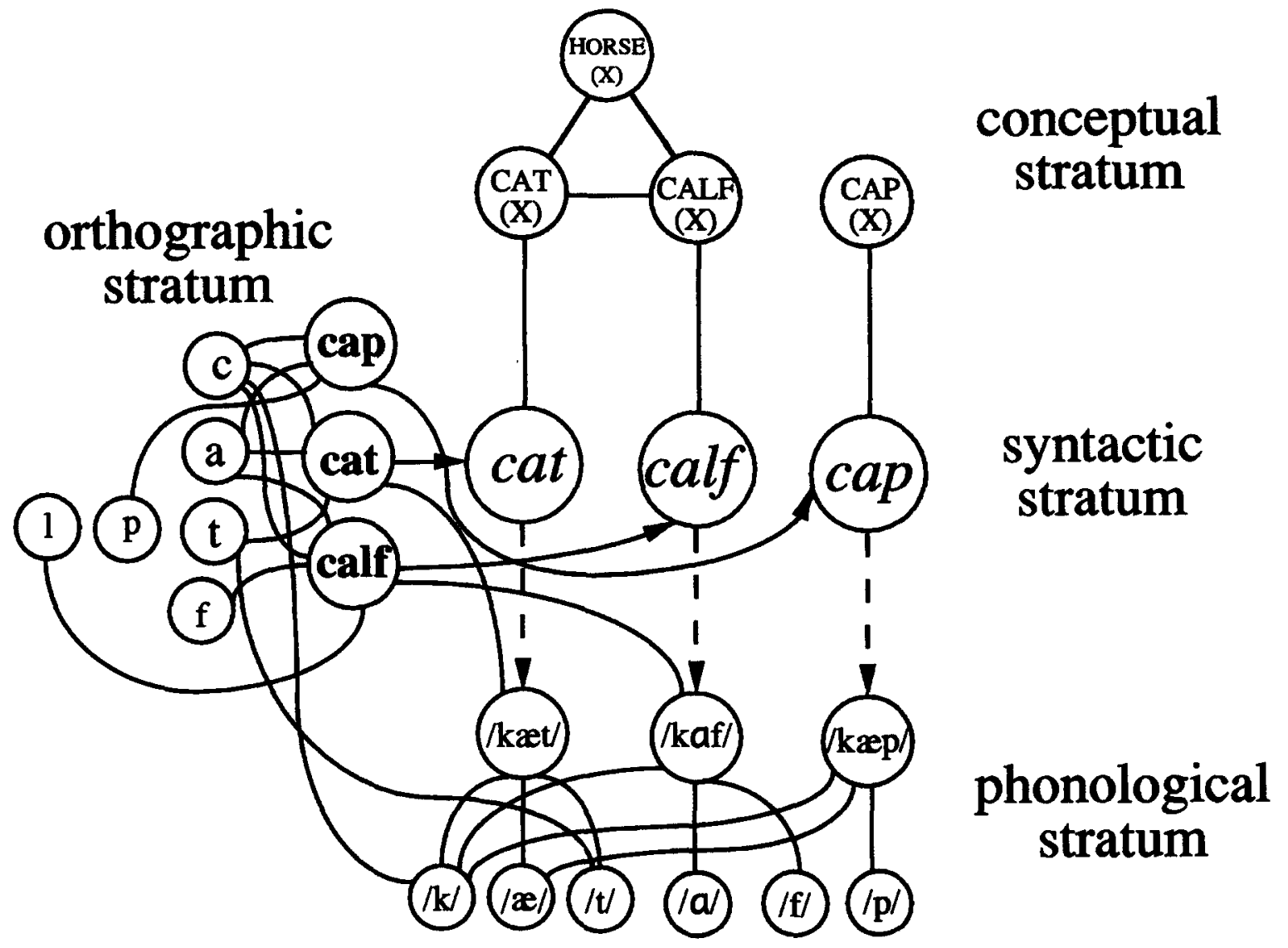

Figure 2. Fragment of the lexical network for the words cat, calf, and cap. Note that some of the links between the orthographic substratum and the phonological substratum are left out of the figure to avoid complicating it too much. For the same reason, the labels on the links assumed by Roelofs $(1992,1993)$ are omitted as well.

model, phonological mediation of visual word recognition must engage phonological input representations (which are presumed, but not depicted in Figures 1 and 2) rather than phonological output representations. The distinction between input and output phonological representations is supported by empirical evidence from normal and aphasic speakers (e.g., Shallice, McLeod, \& Lewis, 1985; see Caplan, 1992; Monsell, 1987, for reviews). Also, the distinction between input and output representations allowed Levelt et al. (1991b) to obtain a quantitative fit of their serial model and relevant latency data. Thus, Route a in Figure 1 may involve a direct mapping of orthographic forms onto lemmas or an indirect mapping by means of phonological input representations. For reasons of simplicity, our argument is in terms of a direct mapping of orthographic forms onto lemmas.

Starreveld and La Heij's (1995) assumption that serial models should predict additive effects of semantic and orthographic relatedness was based on the presupposition that lemmas are not activated by orthographic codes in such models. If lemmas are not activated by orthographic codes, the interaction must be due to feedback from phonological encoding to lemma retrieval. However, serial models (e.g., Levelt et al., 1991a, 1991b; Schriefers et al., 1990) do not deny that lemmas are activated by orthographic codes. Starreveld and La Heij's statement that in serial models "no word forms other than the one selected for production become activated" (1995, p. 694) is not relevant here. The seriality claim concerns the mapping of lemmas onto output phonological forms (i.e., the relationship between the retrieval of the target lemma and its phonological encoding). This should not be confused, as Starreveld and La Heij apparently did, with the mapping of orthographic input forms onto the mental lexicon (i.e., the relationship between visual word-form perception and lemma retrieval). This confusion seems to be the basis for their belief that serial models must predict additive effects. However, output and input mappings should be distinguished in models of speech production (and are distinguished in Roelofs', 1992, 1993, model). The mapping of lemmas onto output phonological forms is represented by the dashed lines with arrows in Figure 2, and the mapping of input orthographic forms onto lemmas is represented by the plain lines with arrows.

The interaction between semantic and orthographic relatedness is explained in Roelofs' $(1992,1993)$ model as follows. In modern accounts of visual word recognition (e.g., McClelland \& Rumelhart, 1981, explicitly referred to as a model for the orthographic substratum by Roelofs, 1992, p. 117), a perceived 
written word not only activates its own orthographic code in memory but also that of its orthographic neighbors, both at the input orthographic stratum and at the lexico-semantic (i.e., lemma) level. For example, the written distractor calf will activate the orthographic nodes $c, a, l, f$, and calf and the lemma node calf, and to some extent the orthographic form and lemma of orthographic neighbors such as cat and cap. Similarly, the written distractor word horse will activate its own orthographic nodes and lemma, and somewhat less the form and lemma of orthographic neighbors such as house.

Consequently, the orthographic representation of a distractor that is both semantically and orthographically related to the target will activate its own lemma and also that of the target (e.g., the orthography of the distractor calf activates the lemma of calf and also that of cat). The same holds for a distractor that is orthographically but not semantically related to the target (e.g., the orthography of the distractor cap activates the lemma of cap and also that of cat). In contrast, the orthographic representation of a distractor that is semantically but not orthographically related to the target will activate its own lemma but not that of the target (e.g., the orthography of the distractor horse activates the lemma of horse but not that of cat). The same holds for a distractor that is neither semantically nor orthographically related (e.g., the orthography of the distractor house activates the lemma of house but not that of cat).

Earlier, we explained that, as a result of the connections at the conceptual stratum and the resulting convergence of activation on the distractor lemma, the distractor horse will be a stronger competitor to the target lemma cat than the distractor house. For the same reason, the distractor calf will be a stronger competitor to the target lemma cat than the distractor cap. However, because of the orthographic overlap, calf and cap will not only activate their own lemmas but also the lemma of the target cat. Thus, the distractors calf and cap will strengthen the target lemma node cat in the competition with the lemma nodes of calf and cap (compared with the distractors horse and house). Written distractors that are orthographically related to the target will help the target lemma node compared with written distractors that are not orthographically related to the target. As we demonstrate below, when lemma retrieval has nonlinear aspects (e.g., a nonlinear activation dynamics, which holds for Roelofs', 1992, 1993, model), orthographic overlap may help semantically related distractors (i.e., calf) more than semantically unrelated ones (i.e., cap). Nonlinearities are also assumed in Starreveld and La Heij's (1995) nonserial account of the interaction. The nonlinearity at the lemma level explains the interaction between semantic and orthographic relatedness observed by Starreveld and La Heij. In short, under this view of serial access, interaction rather than additivity is predicted. What matters is how semantic and orthographic factors combine at the lemma level rather than whether there is feedback between phonological encoding and lemma retrieval.

\section{Computer Simulations}

Computer simulations supported the above theoretical analysis. The simulations were run in the same way and with the same parameter values as the simulations reported by Roelofs (1992, 1993). Our simulations used networks consisting of orthographic nodes (e.g., cat), lemma nodes (e.g., cat), and lexical-concept nodes (e.g., CAT(x)), as shown in Figure 2. A semantic field consisted of three concepts (e.g., $\operatorname{CAT}(\mathrm{X})$, $\operatorname{CALF}(x)$, and HORSE(x)), which were connected to each other and to their lemma nodes in a bidirectional manner. Orthographic nodes such as cat, calf, and horse were connected in a unidirectional manner to their lemma nodes. The presentation of a picture and a distractor word was simulated by assigning a jolt of external activation to the concept node representing the output from picture perception and to the orthographic node representing the output from letter perception. Orthographic overlap was simulated by assigning the full external input to the orthographic node of the distractor word and a proportion of this input to the orthographic node of the target word. For example, in case of distractor calf, the node calf received the full amount of external input, whereas the node cat received a proportion, alpha, of this input. Thus, the parameter, alpha, stands for orthographic overlap between the target and the distractor. The external input was provided using the number of time steps corresponding to the stimulus-onset asynchrony of Starreveld and La Heij's (1995) experiments (i.e., postexposure of the written distractor by $100 \mathrm{~ms}$ ). Activation was updated following a nonlinear activation function (i.e., a linear summation of inputs combined with a decay factor). The probability of actual selection of the target lemma node in any time step was equal to the ratio of the activation level of the target node and the sum of the activation levels of the target and all the other lemma nodes. On the basis of the spreading equation and the selection probability, the mathematical expectation of the retrieval time of the target lemma was computed for each distractor condition. For details (e.g., the equations for the activation dynamics, the selection probability, and the expected lemma retrieval time, and also the parameter values) see Roelofs (1992, 1993).

In the serial account, the locus of the main effect of orthographic relatedness is the level of phonological output codes. Mean production latencies represent a probabilistic mixture of trials, with a certain proportion of trials being in the stage of lemma retrieval and the remaining trials being in the stage of phonological encoding (cf. Levelt et al., 1991b). The simulation of the lemma level effects incorporates the assumption about this mixture by means of the selection ratio, making lemma retrieval time a random variable. Note that the net result may differ between written and spoken distractors, given that spoken words have an extension over time (cf. Schriefers et al., 1990).

Figure 3 illustrates how the size of the semantic effect in the model depends on the size of alpha. The parameter, alpha, is the proportion of shared orthographic input (i.e., the jolt of external activation assigned to the orthographic nodes) in the simulations. Thus, alpha is an index of the degree of orthographic overlap between a target (e.g., cat) and a distractor (e.g., cap, calf, horse, house). The parameter, alpha, does, of course, not necessarily correspond to the number of shared letters. Figure 3 shows that when the external jolt of activation for the orthography is not shared by the target and the distractor (i.e., $0 \%$ orthographic overlap, as is the case for the 


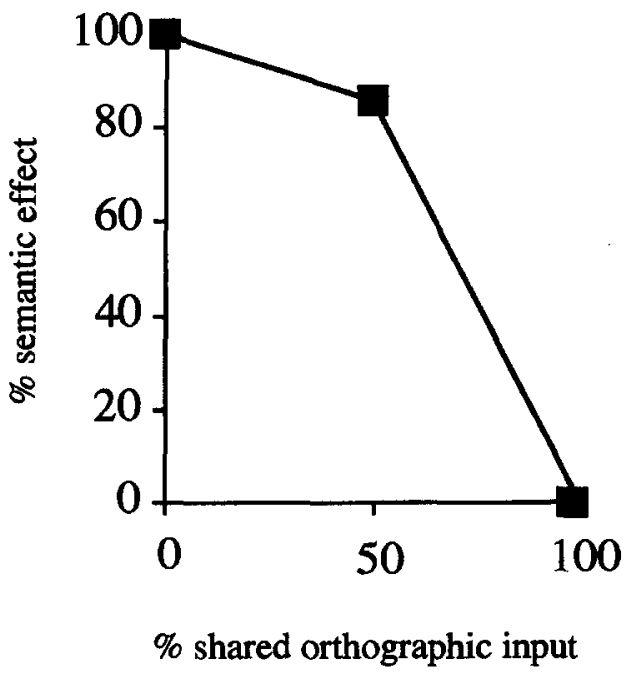

Figure 3. Size of the semantic effect (in terms of the percentage of the standard effect size) as a function of the shared orthographic input (parameter alpha) in the computer simulations. The left-most point shows the semantic-inhibition effect for orthographically unrelated distractors (e.g., horse vs. house for the retrieval of cat), set to $100 \%$. The other data points represent the size of the semantic effect relative to the $100 \%$ as a function of parameter alpha.

distractors horse and house for the target cat), the model produces a full-blown semantic inhibition effect (i.e., $100 \%$ of the standard semantic inhibition effect). In contrast, when almost the entire orthographic input is shared (as is the case for the distractors calf and cap for the target cat), the semantic inhibition effect is canceled out (i.e., $0 \%$ of the standard semantic inhibition effect is left). In short, the simulations show that the size of the semantic effect is reduced by orthographic overlap. ${ }^{1}$ This interaction between semantic and orthographic relatedness corresponds precisely to what Starreveld and La Heij (1995) observed. This interaction is obtained in simulations with lemma nodes and without feedback from phonological encoding to lemma retrieval. In contrast, Starreveld and $\mathrm{La}$ Heij argued that the interaction requires a model of lexical access either without lemma retrieval or with feedback from phonological encoding to lemma retrieval. The simulation outcomes support our claim that this conclusion is not warranted. Instead, we showed that a model of lexical access in speech production with a lemma level and without feedback from phonological encoding to lemma retrieval can also produce the observed interaction. The simulation is an existence proof. It shows that there is a version of the serial access model that can cope with the interaction observed by Starreveld and La Heij.

\section{Conclusion}

In conclusion, Starreveld and La Heij's (1995) prediction of additive effects of semantic and orthographic similarity for serial access was based on an oversimplified view of serial models of access. We argue that their rejection of the seriality view is not warranted. Rather, as we have demonstrated, the observed interaction between semantic and orthographic fac- tors can be accounted for by a serial model of lexical access in speech production.

\footnotetext{
${ }^{1}$ We did not intend to capture the data quantitatively. Starreveld and La Heij (1995) argued that serial access models cannot account for the interaction at all, but not that a serial model cannot fit the data quantitatively. We have used an existing model to illustrate our point without reestimating some of the model's parameters (which would be quite acceptable, given that different experiments and a different task were involved). In Starreveld and La Heij's picture naming experiment, the semantic effect was reduced by half, and in their definition naming experiment, it was fully canceled out by orthographic relatedness.
}

\section{References}

Caplan, D. (1992). Language: Structure, processing, and disorders. Cambridge, MA: MIT Press.

Coltheart, M., Curtis, B., Atkins, P., \& Haller, M. (1993). Models of reading aloud: Dual-route and parallel-distributed-processing approaches. Psychological Review, 100, 589-608.

Dell, G. S., \& O'Seaghdha, P. (1991). Mediated and convergent lexical priming in language production: A comment on Levelt et al. (1991). Psychological Review, 98, 604-614.

Jared, D., \& Seidenberg, M. (1991). Does word identification proceed from spelling to sound to meaning? Journal of Experimental Psychology: General, 120, 358-394.

Levelt, W. J. M., Schriefers, H., Vorberg, D., Meyer, A. S., Pechmann, T., \& Havinga, J. (1991a). Normal and deviant lexical processing: A reply to Dell and O'Seaghdha (1991). Psychological Review, 98, 615-618.

Levelt, W. J. M., Schriefers, H., Vorberg, D., Meyer, A. S., Pechmann, T., \& Havinga, J. (1991b). The time course of lexical access in speech production: A study of picture naming. Psychological Review, 98, 122-142.

Lupker, S. J. (1982). The role of phonetic and orthographic similarity in picture-word interference. Canadian Journal of Psychology, 36, 349-367.

MacLeod, C. M. (1991). Half a century of research on the Stroop effect: An integrative review. Psychological Bulletin, 109, 163-203.

McClelland, J. L., \& Rumelhart, D. E. (1981). An interactive activation model of context effects in letter perception: Part 1. An account of basic findings. Psychological Review, 88, 375-407.

Monsell, S. (1987). On the relation between lexical input and output pathways for speech. In D. A. Allport, D. MacKay, E. Scheerer, \& W. Prinz (Eds.), Language production and perception. London: Academic Press.

Pachella, R. G. (1974). The interpretation of reaction time in information-processing research. In B. H. Kantowitz (Ed.), Human information processing: Tutorials in performance and cognition. Hillsdale, $\mathrm{NJ}$ : Erlbaum.

Rayner, K., \& Springer, C. J. (1986). Graphemic and semantic similarity effects in the picture-word interference task. British Journal of Psychology, 77, 207-222.

Roelofs, A. (1992). A spreading-activation theory of lemma retrieval in speaking. Cognition, 42, 107-142.

Roelofs, A. (1993). Testing a non-decompositional theory of lemma retrieval in speaking: Retrieval of verbs. Cognition, 47, 59-87.

Schriefers, H., Meyer, A., \& Levelt, W. J. M. (1990). Exploring the time-course of lexical access in language production: Picture-word interference studies. Journal of Memory and Language, 29, 86-102

Seidenberg, M. S., \& McClelland, J. L. (1989). A distributed, developmental model of word recognition and naming. Psychological Review, $96,523-568$. 
Shallice, T., McLeod, P., \& Lewis, K. (1985). Isolating cognitive modules with the dual-task paradigm: Are speech perception and production separate processes? Quarterty Joumal of Experimental Psychology: Human Experimental Psychology, 37(A), 507-532.

Starreveld, P. A., \& La Heij, W. (1995). Semantic interference, orthographic facilitation, and their interaction in naming tasks. Joumal of Experimental Psychology: Leaming, Memory, and Cognition, $21,686-698$.
Sternberg, S. (1969). The discovery of processing stages: Extensions of Donders' method. Acta Psychologica, 30, 276-315.

Received December 14, 1994 Revision received February 15, 1995 Accepted February 17, 1995

\section{American Psychological Association SUBSCRIPTION Claims INFORMATION}

Today's Date:

We provide this form to assist members, institutions, and nonmember individuals with any subscription problems. With the appropriate information we can begin a resolution. If you use the services of an agent, please do NOT duplicate claims through them and directly to us. PLEASE PRINT CLEARLY AND IN INK IF POSSIBLE.

\begin{tabular}{l}
\hline PRINT FULL NAME OR KEY NAME OF INSTTIUTION \\
\hline ADDRESS \\
\hline STTY STATECOUNIRY
\end{tabular}

YOUR NAME AND PHONE NUMBER

TITLE

Thank you. Once a claim is received and resolved, delivery of replacement issues routinely takes $4-6$ weeks.

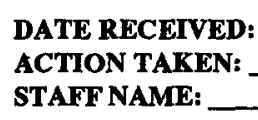

DATE RECEIVED:

ACTION TAKEN: STAFF NAME:

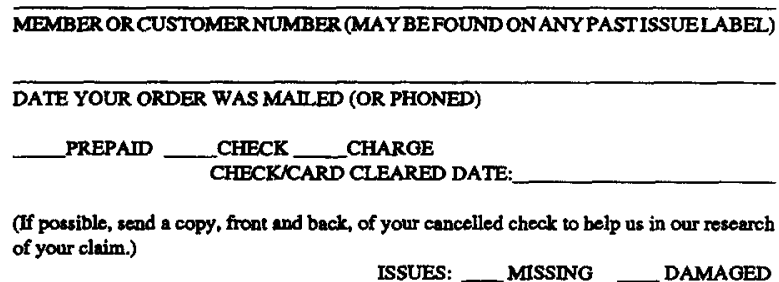

VOLUME OR YEAR

(TO BE FULED OUT BY APA STAFT)

DATE OF ACTION:

INV. NO. \& DATE:

LABEL NO. \& DATE:

Send this form to APA Subscription Claims, 750 First Street, NE, Washington, DC 20002-4242

PLEASE DO NOT REMOVE. A PHOTOCOPY MAY BE USED. 